\title{
Recommendations for Epidemiological Research in ME/CFS from the EUROMENE Epidemiology Working Group
}

Authors: *Joint first authors, $\neq$ Joint last authors

1. Kathleen Mudie* - London School of Hygiene and Tropical Medicine, London, UK. Kathleen.Mudie1@Ishtm.ac.uk; https://orcid.org/0000-0001-7950-8680

2. Fernando Estévez-López* - Erasmus MC University Medical Center, Rotterdam, Netherlands. fer@estevez-lopez.com; https://orcid.org/0000-0003-2960-4142

3. Slobodan Sekulic - Medical Faculty Novi Sad, Novi Sad, Serbia.nadlak@yahoo.com ; https://orcid.org/0000-0001-7889-310X

4. Andrejs Ivanovs - Riga Stradins University, Riga, Latvia. Andrejs.Ivanovs@rsu.lv ; https://orcid.org/0000-0002-7376-3776

5. Nuno Sepulveda - Centre of Statistics and Application of University of Lisbon, Lisbon, Portugal. nunosep@gmail.com; https://orcid.org/0000-0002-8542-1706

6. Pawel Zalewski - Nicolaus Copernicus University, Torun; Collegium Medicum, Bydgoszcz, Poland. p.zalewski@cm.umk.pl; https://orcid.org/0000-0001-8453-7785

7. Anne Marit Mengshoel - University of Oslo, Oslo, Norway. a.m.mengshoel@medisin.uio.no; https://orcid.org/0000-0003-1800-4440

8. Jean-Dominique De Korwin - Lorraine University and Nancy University hospital, Hôpitaux de Brabois - Bâtiment Philippe, Nancy, France. jean-dominique.dekorwin@univ-lorraine.fr ; https://orcid.org/0000-0003-2998-2207

9. Natasa Hinic Capo - University of Novi Sad, Faculty of Medicine, Oncology Institute of Vojvodina, Novi Sad, Serbia. hiniceva.ns@gmail.com ; https://orcid.org/0000-0001-7547-222X

10. Jose Alegre-Martin - Vall d'Hebron University Hospital (VHIR), Barcelona, Spain. jalegre@vhebron.net; https://orcid.org/0000-0002-7582-7585

11. Jesus Castro-Marrero - Vall d'Hebron University Hospital (VHIR), Barcelona, Spain. jesus.castro@vhir.org; https://orcid.org/0000-0002-2481-3052

12. Modra Murovska - Riga Stradins University, Riga, Latvia. Modra.Murovska@rsu.lv ; https://orcid.org/0000-0003-0971-1784

13. Luis Nacul - London School of Hygiene and Tropical Medicine, London, UK. Luis.Nacul@Ishtm.ac.uk; https://orcid.org/0000-0003-1411-8088

14. Eliana Mattos Lacerda $\neq$ - London School of Hygiene and Tropical Medicine, Keppel Street, London, UK. Eliana.Lacerda@Ishtm.ac.uk ; https://orcid.org/0000-0002-5077-7868 - Corresponding author On behalf of EUROMENE

\footnotetext{
Abstract

The European Network on Myalgic Encephalomyelitis/Chronic Fatigue Syndrome (EUROMENE) was established after a successful grant application to the European Cooperation is Science and Technology (COST). This network aimed to assess the existing knowledge and/or experience on health care delivery for people with Myalgic Encephalomyelitis/Chronic Fatigue Syndrome (ME/CFS) in the European countries and worldwide, and to enhance coordinated research and health care provision in this field.

The EUROMENE proposal, was based on the establishment of interrelated working groups (WGs), where the participants contributed with specific knowledge and viewpoints according to their specialties and/or areas of interest. In this paper we outline the work of a multidisciplinary team of researchers, including epidemiologists, clinicians, statisticians, biomedical scientist and heath
} 
economists, who set out their recommendations to guide data acquisition for ME/CFS research, aiming to standardise data collection and improve epidemiological research.

Key words: Myalgic Encephalomyelitis/Chronic Fatigue Syndrome (ME/CFS), Data Collection Standardisation, Research Guidelines, Europe.

\section{Introduction}

The European Network on Myalgic Encephalomyelitis/Chronic Fatigue Syndrome (EUROMENE) was established after a successful grant application to a continuous open call from the European Cooperation in Science and Technology (COST) - through the instrument named COST Action.

Initially designed by a group of ME/CFS researchers and health professionals, the proposed network was submitted to COST in 2015 aiming to assess the existing fragmented knowledge and/or experience on health care delivery for people with Myalgic Encephalomyelitis/Chronic Fatigue Syndrome (ME/CFS) in the European countries and worldwide, and to enhance coordinated research and health care provision in this field.

ME/CFS is characterised by intolerance to efforts expressed by profound or pathological fatigue, malaise and other symptoms aggravated by physical or cognitive efforts at intensities previously well tolerated by the individual. Intolerance to efforts may be experienced immediately or typically be delayed for hours or a day or two after exertion and is associated with slow recovery, which may extend to one or more days (post-exertional malaise (PEM) or aggravation of symptoms following exertion ( Carruthers et al., 2011; Carruthers, DeMeirleir, et al., 2003; Institute of Medicine (IOM), 2015). Other key symptoms include unrefreshing sleep, cognitive manifestations, orthostatic intolerance and pain, including muscle and joint pain and headaches. The symptoms are persistent or recurrent over long periods of time, and lead to a significant reduction in previous levels of functioning. Diagnosis is clinical, owing to the absence of biomarkers, and based on detailed clinical history and physical examination by a competent clinician ( Carruthers et al., 2011; Carruthers, De Meirleir, et al., 2003). There is no causal treatment for the disease. With symptom-oriented support many improve with time or learn to manage their illness. There is little evidence on long term prognosis. However, full recovery is not the norm, particularly in adults ( Carruthers, De Meirleir, et al., 2003; Institute of Medicine, 2015; Nacul et al., 2020).

Prevalence rate have been estimated as between 0.2 and $0.7 \%$ (Bakken et al., 2014; Jason et al., 1999; Nacul et al., 2011; Vincent et al., 2012) with incidence rate of 0.015 new cases/1000-year ( Nacul et al., 2011). This could represent between 1 million and over 5 million people, probably around 3 million in the European continent living with ME/CFS. However, there are no Europe-wide estimates of disease burden (Estévez-López et al., 2018). A much larger number of people will have chronic fatigue for other reasons, and many of them will also be significantly incapacitated. At least 2/3 of the cases are in women ( Nacul et al., 2011; Valdez et al., 2018) with young people in their most productive phases of life being preferentially affected. However, ME/CFS was reported in all age groups (Valdez et al., 2018). Quality of life of those with ME/CFS is on average lower than with other chronic or disabling diseases, such as MS (Kingdon et al., 2018), cancer, depression( Nacul et al., 2011), diabetes, epilepsy, or cystic fibrosis (Ingerski et al., 2010; Kennedy et al., 2010; Varni et al., 2007), the latter being related to children (Winger et al., 2015). Economic costs are considerable (Hunter et al., 2017; Jason et al., 2008; Lloyd \& Pender, 1992; Valdez et al., 2018), with repercussions for the individual affected and their families and society, as well as to educational and occupational services. 
The methodological approach presented in the EUROMENE proposal, was based on the establishment of interrelated working groups (WGs), where the participants joining the network would contribute with specific knowledge and viewpoints according to their specialties and/or areas of interest. In this paper we outline the work of a multidisciplinary team of researchers, including epidemiologists, clinicians, statisticians, biomedical scientist and heath economists, who set out their recommendations to guide data acquisition for ME/CFS research, aiming to standardise data collection and improve epidemiological research. An overarching principle of the present work was to suggest tools for collecting standardised data on the presence and severity of cardinal ME/CFS symptoms and dysfunctions that may impose a burden on patients' well-being and health-related quality of life. To ensure scalability of the suggested assessments, including applicability in population-based studies, most of them are based on self-reports. When circumstances (both resources and needs) allow it, additional objective measurements are suggested to obtain a more comprehensive picture of ME/CFS.

\section{ME/CFS Standardised Research Guide}

The process of standardising data collection tools across participating European countries involved discussions between working group members, followed by consultation with all EUROMENE members. Selection of data variables was based on the following criteria: freely available and easy to use, validated and relevant for ME/CFS research, and consistent with current international practice in research. Having in mind relevance beyond European countries, topic-driven data elements such as the Common Data Elements (CDE) Project developed by the National Institute of Neurological Disorders and Stroke (NINDS) for ME/CFS clinical research were reviewed (https://www.commondataelements.ninds.nih.gov/MECFS.aspx\#tab=Data Standards ).

The discussion began with a review of the literature of the current landscape of international ME/CFS research (Estévez-López et al., 2018). Data collection tools presently used within participating European countries were outlined by country representatives. Working group members focussed on four core domain areas for data collection: (i) general core information, (ii) provisional and confirmed diagnosis, (iii) clinical assessment, and (iv) symptom profiling. Within each of these topic areas, the group deliberated and agreed on the most appropriate tools to be used to collect data. Where consensus could not be made, members wrote a report comparing those tools identified. Afterwards, these reports were discussed by the entire group in order to reach a consensus.

Figure 1 outlines data domains to be considered in research. The steps are presented as an example. It should be noted that our recommendation is not to collect all data discussed, only that which is relevant to the purpose of the individual study. However, the use of the recommended data collection tools is essential for maintaining standardised methodologies when the same data are collected (e.g., the assessment of pain levels) by different research groups. 
Figure 1: ME/CFS Standardised Research Guide

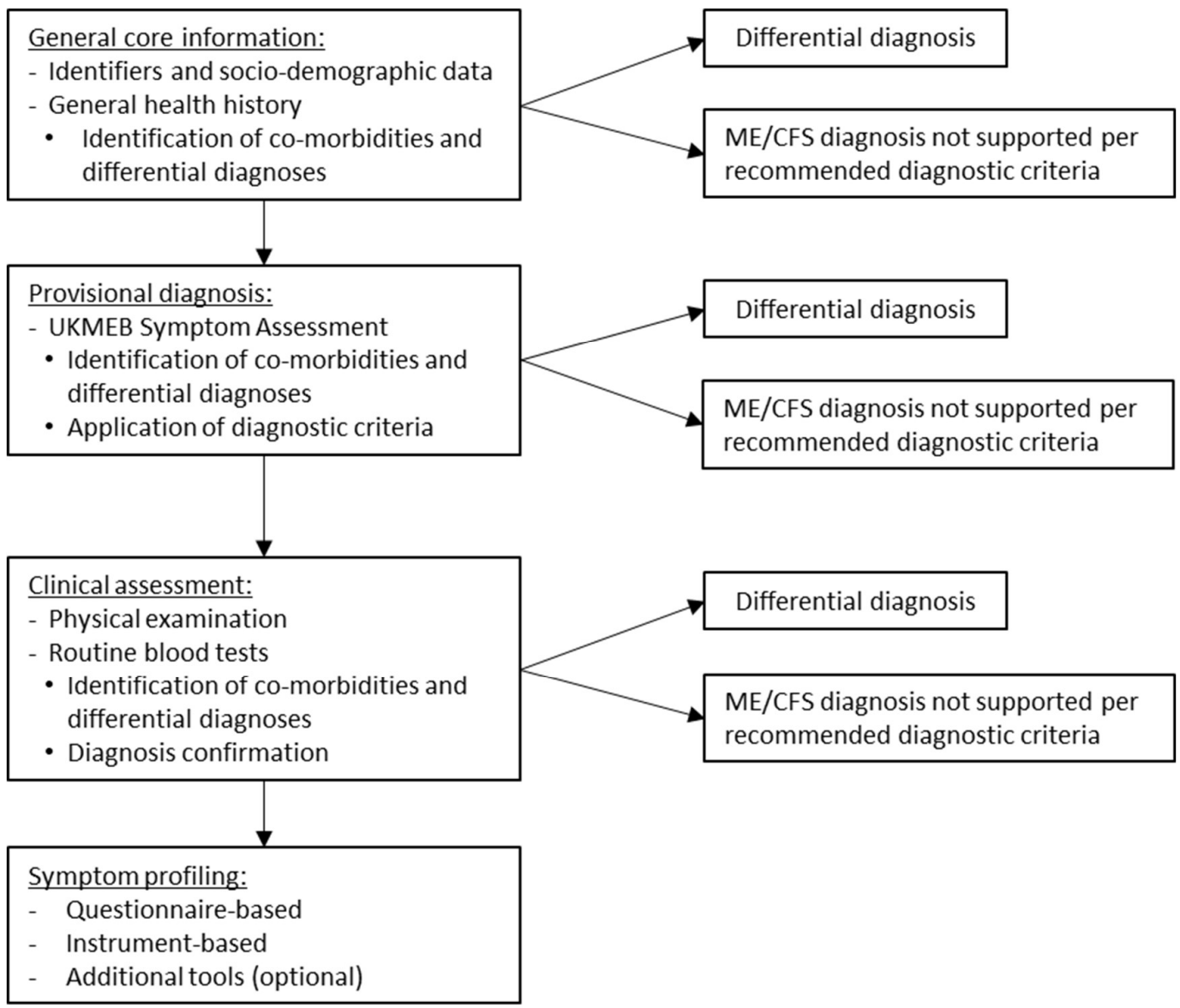

\section{General core information}

We recommend the collection of data related to socio-demographics and the general health history of the participants. The epidemiology working group refers to the socio-economic working group for detailed recommendations on the essential socio-demographic data to be collected (Pheby et al., 2020). In brief, we recommend the collection of gender, date of birth, ethnicity, and level of education, as well as marital status, occupation, income, and living conditions. Given that data from different national health systems lack standardisation and are difficult to access, we agreed on the need to elaborate a set of standardised questions for self-reporting health history that includes a comprehensive assessment of previous and current ill-health to uncover potential co-morbidities, conditions that may justify an alternative diagnosis, and information regarding the onset of the disease (infectious vs non-infectious).

\section{Provisional diagnosis}

A probable or provisional diagnosis can be ascertained based on questionnaire response, although diagnosis confirmation will usually require further assessment or confirmation by a health professional with experience in ME/CFS, which is preferably done through a face-to-face encounter. 
Two available questionnaires that have been used throughout the European participating countries to diagnose ME/CFS are the DePaul Symptom Questionnaire (DSQ) (Jason et al., 2015) and the UK ME/CFS Biobank Symptom Assessment (UKMEBSA) (Lacerda et al., 2017).

The DSQ was developed as a standard questionnaire to consistently assess principal symptoms of $\mathrm{ME} / \mathrm{CFS}$ when diagnosing. The DSQ is a 54-item self-report measure of ME/CFS symptomology, including frequency and severity of symptoms and using three subscales: neuroendocrine, autonomic, and immune symptoms. Symptom frequency over the past six months is rated on a 5point Likert-type scale ranging from (0) 'none of the time' to (4) 'all of the time'. Correspondingly, each symptom's severity over the past six months is also rated on a 5-point Likert-type scale ranging from (0) 'symptom not present' to (4) 'very severe'. A composite score for each subscale, ranging from $0-16$, is then obtained by multiplying the frequency and severity scores.

The UKMEBSA was developed specifically for the recruitment of participants to the UK ME/CFS Biobank and designed to complement the clinical assessment in order to classify individuals according to a variety of ME/CFS case definitions. Most of the UKMEBSA items were taken from validated questionnaires and the symptom list is largely based upon the Canadian Consensus ( Carruthers et al., 2003), Institute of Medicine (Beyond Myalgic Encephalomyelitis/Chronic Fatigue Syndrome: Redefining an IIIness, 2015) and CDC-1994 criteria ( Carruthers et al., 2003; Fukuda et al., 1994; Lacerda et al., 2017). The UKMEBSA is a short questionnaire exploring the presence, duration and impact of fatigue and other symptoms, and includes a 58-item self-report on the presence of $\mathrm{ME} / \mathrm{CFS}$ symptomology, and questions on the presence of diseases that often present with fatigue. It enables the screening of patients for ME/CFS diagnosis according to six different clinical criteria.

To determine which questionnaire would be best for diagnosing cases of ME/CFS, we made a comparison between the DSQ and the UKMEBSA. Both questionnaires inquire about co-morbidities, capture possible exclusionary conditions, and can make a provisional diagnosis using either the CDC1994, the CCC 2003, or the IOM criteria. The major difference is that the DSQ also asks about severity and frequency of symptoms, while the UKMEBSA asks only about presence of symptoms, which make the latter simpler to use. Therefore, we recommend the choice of questionnaire to depend on the study in question.

We note here that the clinical working group of the EUROMENE will be making recommendations on standardised diagnostic criteria and application of that criteria. The provisional diagnosis is intended as a systematic approach to ascertain cases of ME/CFS for research purposes. While clinical diagnostic criteria might be broader (less sensitive) or even different in the different participating countries, there is a need for a standardised research diagnostic criteria that is able to select a more homogenous group of patients in order to select more comparable participants across the settings ( Jason et al., 2017).

\section{Clinical assessment}

The clinical assessment is an essential part of the diagnosis workout (IOM, 2015) and is an aid to identify co-morbidities and exclusionary conditions that could otherwise explain the symptoms (Hives et al., 2017; Jason et al., 2010). Considering the lack of biomarkers, in addition to questionnaire, we suggest a brief clinical assessment to comply with the suggested diagnostic criteria. If participants have completed initial questionnaires prior to the assessment (Figure 1), the encounter is an opportunity to clarify answers given and to confirm or to explore reported symptoms in depth (Kingdon et al., 2018).

The physical assessment may include: 
- A general physical examination, which may be normal, even though some patients present with general aspect of tiredness or of being unwell. Specific signs may help differential diagnosis or co-morbidities. e.g. anaemia, jaundice, assessment of levels of hydration and nutritional status or any other sign that may suggest ill-health or specific pathology; paleness and cold extremities may be noted.

- $\quad$ Anthropometric measures, including height and weight at a minimum.

- Blood pressure and heart rate taken at one-minute intervals with the participant first lying down for five minutes and then standing still for up to ten minutes (or until no longer able), with consideration to dropping the first reading. For research with emphasis on autonomic function, a beat-to-beat blood pressure monitoring may be considered. Additionally, active standing (AS) provocation may be performed after 7-10 minutes of rest. The blood pressure response should be analysed for min. 2-3 minutes, if it is possible should be prolonged up to 10-13 minutes to characterise postural orthostatic tachycardia syndrome (POTS). Patients with severe symptoms may be unable to be tested with these procedures. This procedure should be performed according to ANS examination.;

- Pulse oximetry;

- A specific examination covering main body systems (skin, head and neck, heart and circulation, respiratory, abdomen, and limbs) and could include neck palpitations, oropharynx, lymph nodes (neck, supra-clavicular, axillar), joints and neurological examination; the latter to include at a minimum the quick assessment of mental status using a validated questionnaire (for example the Mini-Mental State Examination (MMSE) or the Addenbrooke's Cognitive Examination - ACE-III), coordination and gait, cranial nerves, cerebellar function, muscle strength and tone, sensory function, and reflexes.

- A directed examination targeted according to general health history, findings from the general clinical examination and specific symptoms reported.

- Hand grip strength, a component of physical fitness which is defined as a set of attributes that people have or achieve that relate to the ability to perform physical activities (Caspersen et al., 1985), is a powerful marker of health in both the general population (García-Hermoso et al., 2019; Harber et al., 2017; Ortega et al., 2008; Rodriguez-Ayllon et al., 2019; Ruiz et al., 2008) and chronic diseases (Estévez-López et al., 2019; Kato et al., 2012; Ruiz et al., 2009). Field-based tests are often preferred for large-scale studies as they are valid and reliable as well as relatively cheap, safe, and easy to perform and score (CastroPiñero et al., 2019, 2017; Fernandez Santos et al., 2016). Among several possible field-based tests, the usefulness of the hand grip strength (a measurement of muscle strength) has been demonstrated in ME/CFS (Nacul et al., 2018). It reflects the force derived from the combined contraction of extrinsic hand muscles and reduced hand grip strength has been shown to be associated with disability and impaired health-related quality of life (Estévez-López et al., 2015; Gavilán-Carrera et al., 2019; Park et al., 2017) . In one study by Nacul et al, hand grip strength was found to be reduced in people severely affected with ME/CFS (bed- or housebound) compared with people mild/moderately affected (ambulatory), and with healthy controls (Nacul et al., 2018). When circumstances allow to do so, we recommend to objectively measure fitness state by the hand grip strength test (muscle strength) in ME/CFS in EUROMENE participating countries.

Although there is no blood test to diagnose ME/CFS, the following routine blood tests are important to help identify other conditions and co-morbidities: a full blood count, calcium, glucose (either fasting or random glucose or HBA1c), urea and electrolytes, serum creatine kinase, serum ferritin, liver function tests (including total protein, albumin, globulin, bilirubin, alanine, transaminase, alkaline phosphatase), c-reactive protein or ESR, Immunoglobulin G/M/A, anti-nuclear antibodies, rheumatoid factor or anti-cyclic citrullinated peptide (anti-CCP) antibodies, thyroid function tests (including T3, T4, thyroid-stimulating hormone, and thyroid peroxidase antibody test), basal 
cortisolemia, coeliac disease screening (e.g. tissue transglutaminase antibody), and B12 and folate concentrations. A urinalysis should also be performed; we recommend using ten-parameter test strips that measures blood, bilirubin, urobilinogen, ketone, protein, nitrite, glucose, $\mathrm{PH}$, specific gravity, and leucocytes. Other tests may be required according to symptoms and clinical findings.

\section{Diagnosis confirmation}

The confirmation of the ME/CFS diagnosis is achieved by combining the use of a standard questionnaire (provisional diagnosis) and clinical assessment (identify co-morbidities and exclusionary conditions that could otherwise explain the symptoms). While further discussions are taking place across EUROMENE, with the leadership of the Clinical Working Group, we propose that any of the Canadian Consensus ( Carruthers et al., 2003), CDC-1994 (Fukuda et al., 1994) and the IOM (Institute of Medicine, 2015) criteria are acceptable for case diagnosis, although the combination of the Canadian Consensus and IOM criteria are preferable as these require postexertional malaise symptoms. We also note that combined use of these 3 criteria provides a more specific diagnosis, which will often be desirable for research purposes ( Nacul et al., 2017). In any case, irrespective of the choice of diagnostic criteria, which will be referred to the clinical working group, we recommend that ascertainment of diagnosis by multiple criteria is done and registered on the database, so that they may be referred to if needed (e.g. for further analyses). Those recruited or excluded from research studies that do not meet the chosen diagnostic criteria are referred to "non- ME/CFS cases", or "non-ME/CFS chronic fatigue cases" if chronic fatigue is present. The latter may be either attributable to a specific alternative diagnosis (e.g. MS- or cancer- related CF) or be "life-style' related or of "unknown cause".

\section{Symptom profiling}

The majority of symptoms reported are post-exertional malaise, extreme fatigue, cognitive dysfunction, orthostatic intolerance, and impaired sleep (Twisk, 2015). To ensure feasibility in largescale research, the recommended tools rely on self-reports and are designed to assess a patient's symptoms in two ways: (i) questionnaire-based symptom profiling and (ii) instrument-based symptom profiling. Additional tools for collecting data pertaining to symptom profiling are also recommended as resources allow. To do so, all ME/CFS research studies across participating countries of the EUROMENE network should use these as a guide to enhance comparability of data and interpretability of findings, keeping in mind that, depending on the aim of each study, not all the measurements are compulsory in every study.

\subsection{Questionnaire-based symptom profiling}

The questionnaires recommended in Table 1 are freely available for use. Where possible, epidemiological parameters of validity and reliability will be reported. These are intended as a guide and should be tailored for each population. We suggest questionnaires be validated in native languages, if necessary.

Table 1. Recommended data collection tools for questionnaire-based profiling of post-exertionalmalaise, pain, neurological, neurocognitive, neuroendocrine, immune, sleep, autonomic function, emotional/behavioural, and quality of life symptoms

Recommended data collection tool

\section{Symptom domains}

\section{Description}




\begin{tabular}{|c|c|c|}
\hline $\begin{array}{l}\text { UKMEB Participant } \\
\text { Questionnaire } \\
\text { (UKMEBQ) }\end{array}$ & $\begin{array}{l}\text { post-exertional } \\
\text { malaise } \\
\text { pain } \\
\text { neurocognitive } \\
\text { neuroendocrine } \\
\text { immune } \\
\text { daytime sleepiness }\end{array}$ & $\begin{array}{ll}\text { - } & \text { 58-item } \\
\text { - } & \text { measures presence and severity of } \\
& \text { symptoms in previous } 7 \text { days }\end{array}$ \\
\hline $\begin{array}{l}\text { Fatigue Severity } \\
\text { Scale (FSS) }\end{array}$ & fatigue & $\begin{array}{l}\text { - } 9 \text {-item } \\
\text { measures impact of fatigue on activities and } \\
\text { - } \text { difestyle } \\
\text { in multinguishes fatigue in ME/CFS from fatigue } \\
\text { depression }\end{array}$ \\
\hline $\begin{array}{l}\text { Pittsburgh Sleep } \\
\text { Quality Index }\end{array}$ & Sleep & $\begin{array}{ll}\text { - } & \text { 19-item, 5-supplementary for bed } \\
\text { partners/roommates } \\
\text { - } \\
\text { measures } 7 \text { components of sleep quality } \\
\text { over past } 30 \text { days } \\
\text { - } \quad \text { higher numbers indicate poorer sleep } \\
\text { quality } \\
\text { - } \quad \text { reliable and valid in people with ME/CFS }\end{array}$ \\
\hline COMPASS-31 & Autonomic function & $\begin{array}{ll}\text { - } & \text { 31-item } \\
\text { - } & \text { measures } 6 \text { clinically relevant domains } \\
\text { - } & \text { internally consistent }\end{array}$ \\
\hline $\begin{array}{l}\text { Beck Depression } \\
\text { Inventory II (BDI-II) }\end{array}$ & $\begin{array}{l}\text { Mental health } \\
\text { (depression) }\end{array}$ & $\begin{array}{ll}\text { - } & \text { 21-item } \\
\text { - } & \text { measures major depression symptoms and } \\
& \text { their severity } \\
\text {. } & \text { recommended by NINDS }\end{array}$ \\
\hline $\begin{array}{l}\text { State-Trait Anxiety } \\
\text { Inventory (STAI) }\end{array}$ & $\begin{array}{l}\text { Mental health } \\
\text { (anxiety) }\end{array}$ & $\begin{array}{ll}\text { - } & \text { 20-item } \\
\text { Possible time-frames: state (right now) or } \\
\text { trait (generally) }\end{array}$ \\
\hline $\begin{array}{l}\text { Positive and } \\
\text { Negative Affect } \\
\text { Schedule }\end{array}$ & Mental health (Affect) & $\begin{array}{l}\text { 20-item, 10-item per each type of affect } \\
\text { Possible time-frames: ranging from state } \\
\text { (right now) to trait (generally) }\end{array}$ \\
\hline $\begin{array}{l}\text { Short Form 36-item } \\
\text { Health Survey (SF- } \\
\text { 36) developed by } \\
\text { RAND }\end{array}$ & $\begin{array}{l}\text { Health-related quality } \\
\text { of life }\end{array}$ & $\begin{array}{l}\text { - } 36 \text {-item } \\
\text { measures } 8 \text { domains of health-related } \\
\text { quality of life and physical and mental } \\
\text { summary components } \\
\text { - used to discriminate different diseases and } \\
\text { levels of severity }\end{array}$ \\
\hline
\end{tabular}

Two available questionnaires that have been used throughout the European participating countries to ascertain ME/CFS diagnosis, based on profiling symptoms. These are the DePaul Symptom Questionnaire (DSQ) (Jason et al., 2015) and the UK ME/CFS Biobank Participant Questionnaire (UKMEBPQ) (Lacerda et al., 2017).

General ME/CFS Questionnaires DePaul Symptom Questionnaire 
The DSQ was developed as a standard questionnaire to consistently assess principal symptoms of ME/CFS when diagnosing. The DSQ is a 54-item self-report measure of ME/CFS symptomology, including frequency and severity of symptoms and using three subscales: neuroendocrine, autonomic, and immune symptoms. Symptom frequency over the past six months is rated on a 5point Likert-type scale ranging from (0) 'none of the time' to (4) 'all of the time'. Correspondingly, each symptom's severity over the past six months is also rated on a 5-point Likert-type scale ranging from (0) 'symptom not present' to (4) 'very severe'. A composite score for each subscale, ranging from $0-16$, is then obtained by multiplying the frequency and severity scores.

\section{UKMEB Participant Questionnaire}

The UKMEBPQ was developed by the UK ME/CFS Biobank. This questionnaire is used to characterise individuals according to a comprehensive array of variables, such as demographic, socio-economic, and severity of symptoms and dysfunctions. The UKMEBPQ is a short questionnaire exploring the presence, duration and impact of fatigue and other symptoms, and includes a 58-item self-report on the presence and the severity of ME/CFS symptomatology. Most of the items were taken from validated questionnaires and the symptom list is largely based upon the following diagnostic criteria: Canadian Consensus ( Carruthers et al., 2003), Institute of Medicine (Beyond Myalgic Encephalomyelitis/Chronic Fatigue Syndrome: Redefining an IIIness, 2015) and CDC-1994 criteria ( Carruthers et al., 2003; Fukuda et al., 1994; Lacerda et al., 2017). It uses seven subscales of symptom clusters: post-exertional malaise, pain, sleep, autonomic dysfunction, neurocognitive dysfunction, neuroendocrine dysfunction, and immune dysfunction (Lacerda et al., 2018). Individuals answer "Absent", "Mild", "Moderate", or "Severe" to a list of 58 symptoms and each symptom is assigned a value of 0 to 3 . Scores are obtained by adding values within the symptom domains and standardising to a scale of 0 to 100 , where " 0 " indicates no symptoms and " 100 " indicates the presence of severe symptoms.

Both the DSQ and the UKMEBPQ have been widely used throughout the European participating countries to profile symptoms in ME/CFS research. When we compared the DSQ and the UKMEBPQ, it was found that they are broadly equivalent, except that the former enquires about symptoms in the previous six months and the latter enquires about symptoms in the previous seven days. The working group is of the view that a shorter period of recall, such as that offered by the latter (i.e in the last week) is preferable, to minimise recall bias and to enable repeated assessments over shorter than 6-month periods, also enabling to capture fluctuation of symptoms over shorter periods of time. Both the UKMEBPQ and DPQ capture data on other variables, such as demographic variables. While the former may be appropriate for European populations, some questions may need to be adapted to specific country variations, e.g. in relation to ethnicity and income.

For symptom domains (post-exertional malaise, pain, neurocognitive dysfunction, neurological dysfunction, neuroendocrine dysfunction, immune dysfunction, and sleep dysfunction) where there are currently no validated and reliable questionnaires that meets our working group criteria for selection, we recommend the use of the UKMEBPQ. In studies where information on the retrospective period of 6-month is appropriate and desirable, such as in cross-sectional studies, then the DPQ may also be appropriate.

Post-exertional malaise (PEM) is considered to be a hallmark symptom of ME/CFS and is related to main diagnostic criteria (Morris \& Maes, 2013). It is characterised by the worsening of ME/CFS symptoms after minimal physical or mental exertion; this worsening can be delayed 24-72 hours or more (Arroll et al., 2014). The UKMEBPQ contains six items pertaining to PEM symptoms and may be used to ascertain severity of this symptom. The DSQ has several questions that are intended to assess PEM, but its description does not match that set out in the IOM or the CCC diagnostic criteria. 
A poll of 750 patients by the Science For ME forum, a place for the patient community to discuss biomedical ME/CFS research, that compared the DSQ and IOM descriptions of PEM showed that most patients considered the IOM description to be more accurate (ScienceforME, 2018).

Pain is a core symptom of ME/CFS. Indeed, $94 \%$ of those with ME/CFS report experiencing widespread muscle pain and $84 \%$ report joint pain (Meeus \& Nijs, 2007). Symptoms of chronic pain can account for up to one third of impairments and restrictions in daily functioning in people with ME/CFS (Meeus \& Nijs, 2007; van der Schaaf et al., 2017). Pain experienced in ME/CFS may vary from being a minor annoyance to being the most disabling symptom of the disease. The UKMEBPQ contains eight items that assess pain, although other studies where pain is a primary outcome may wish to include an objective measure using a validated instrument recommended in section 3.5.2.

Neurological manifestations in ME/CFS may be chronic or sporadic with unpredictable cycles of severity (Chaudhuri \& Behan, 2000). It is therefore imperative to capture the change in these symptoms. The UKMEBPQ contains nine items capable of profiling symptoms of neurological manifestations that can be detrimental to daily functioning.

Neurocognitive impairment, which is commonly reported in ME/CFS, could have implications on daily living such as difficulty with school and/or employment (Shanks et al., 2013). The UKMEBPQ contains nine items related to neurocognitive symptoms to capture problems of memory and information processing that can impair quality of life and contribute to disability.

Neuroendocrine abnormalities are often present in ME/CFS with symptoms across multiple organ systems and have been classified as "energy production/transportation impairments" (IOM, 2015). A greater percentage of people with ME/CFS experience symptoms such as intolerance to temperature extremes, unusually cold extremities, and changes in appetite compared with healthy controls ( Jason \& Brown, 2013). There are six items in the UKMEBPQ to assess the presence and severity of neuroendocrine symptoms in ME/CFS research.

Immunological dysfunction is associated with ME/CFS (Brenu et al., 2011; Hardcastle et al., 2015). Although immunity is best captured through laboratory tests, the UKMEBPQ includes seven items related to immune dysfunction (Table 2). Changes in the presence and severity of these symptoms can be analysed alongside follow-up blood tests for a comprehensive representation.

Daytime sleepiness is not dozing behaviour but is related to fatigue and problematic sleepiness. Within the UKMEBPQ, there is the Epworth Sleepiness Scale consisting of eight questions participants must respond to on a 4-point scale (0-3) their usual chances of dozing off or falling asleep while engaged in different activities. The score is a sum of the eight items, where 0 indicates a low average sleep propensity in daily life and 24 indicates a high average. The internal consistency of this scale has been found to have a mean Cronbach's alpha of 0.82 and the test-retest reliability has been found to have an intraclass correlation coefficient between 0.81 and 0.93 (Johns, n.d.).

\section{Fatigue assessment}

Fatigue is a major disabling symptom in ME/CFS and is notoriously difficult to define as it is nonspecific and highly subjective (Krupp et al., 1989). Numerous fatigue scales have been created, however, the Fatigue Severity Scale (FSS) is the most commonly used validated fatigue-specific questionnaire (Valko et al., 2008). The FSS is a 9-item measurement of the impact of fatigue on the patient's activities and lifestyle over the preceding week and was developed and validated initially in people with multiple sclerosis and systemic lupus. Participants are asked to rate each item on a 7point Likert-type scale ranging from (1) 'strongly disagree' to (7) 'strongly agree'. The FSS scores is 
computed as the average of its nine items, with a minimum score being 1 and a maximum being 7 and the higher the score, the greater the fatigue. The advantages of the FSS are that it is brief to administer (less than 5 minutes), it is capable of differentiating fatigue in ME/CFS from fatigue in multiple sclerosis as well as from fatigue in depression, and it is sensitive to treatment changes in ME/CFS (NINDS Common Data Elements, 2018).

\section{Sleep Quality assessment}

Sleep is essential for optimal health. In ME/CFS, unrefreshing sleep as well as disturbed or restless sleep is a prominent symptom (Rahman et al., 2011). We recommend the Pittsburgh Sleep Quality Index (PSQI), a free and easy to use questionnaire, in order to assess sleep quality over a one-month period of time (Buysse et al., 1989). The PSQI takes 5-10 minutes to complete and it has been shown to have good reliability and validity in clinical studies with a range of populations, including people with ME/CFS (Fontes et al., 2017; Mollayeva et al., 2016). The advantage of the PSQI is that many of the questions are familiar to people with ME/CFS who often experience the problems raised (NINDS). The limitation is that many may not recall awakening during the night or may not know what specifically awakened them in the night.

The PSQI is a 19-item questionnaire, with five supplemental questions for bed partners or roommates. It consists of seven components of sleep quality over the past 30 days, including subjective sleep quality, sleep latency, sleep duration, habitual sleep efficiency, sleep disturbances, use of sleep medication, and daytime dysfunction (Buysse et al., 1989). Each component score is rated on a 3-point Likert-type scale ranging from (0) indicating good sleep to (3) indicating poor sleep. The component scores are added to provide a global score ranging from 0-21, where higher numbers indicate poorer sleep quality. We recommend both the Epworth Sleepiness Scale within the UKMEBPQ and the PSQI, but one may be more desirable depending on the study question.

\section{Autonomic dysfunction assessment}

Autonomic dysfunction, which includes symptoms such as orthostatic intolerance, dizziness or lightheadedness when standing, palpitations, cold hands and feet, and gastric and irritable bowel type symptoms, is frequently reported by participants with ME/CFS and are all related to altered autonomic nervous system functioning. The COMPASS-31 questionnaire is validated tool to be used in ME/CFS that assesses six clinically relevant domains of autonomic function. It is a refined and markedly abbreviated scoring system, which examines six clinically relevant domains: orthostatic intolerance, vasomotor, secretomotor, pupillomotor, gastrointestinal, and bladder (NINDS Common Data Elements, 2018). Yes/No or Present/Absent questions are scored as 0/1 while Frequency, Severity, and Time course questions are scored on a 0-3 Likert scale. Scores are weighted for each domain and range from 0 to 100, where higher scores indicate more or more severe symptoms.

The COMPASS-31 was designed to provide a global severity score and domain scores that are both clinically and scientifically relevant (Sletten et al., 2012). It demonstrates good internal validity (Cronbach's alpha $=0.92)$, test-retest reliability $(r(s)=0.89 ; p<0.001$ ) and good convergent validity $(r(s)=0.47 ; p<0.001$ ) (NINDS Common Data Elements, 2018). We recommend its use to assess autonomic function of participants with ME/CFS in participating countries.

\section{Mental health assessment}

Depression. The BDI-II is a 21-item questionnaire, evaluating the presence and severity of signs of depression (Beck et al., 1996). Each item is rated on a 4-point Likert-type scale ranging from (0) 
indicating symptom absent to (3) indicating severe symptoms. Thus, the total scores of the BDI-II range from 0 to 63, with higher scores meaning higher signs of depression.

Anxiety. The State-Trait Anxiety Inventory (STAI) assesses the level of anxiety (Spielberger et al., 1970). The STAI is a 20-item self-administered questionnaire, and its score ranges from 20 to 80 , where higher scores indicate greater state anxiety. Participants rate how accurately statements describe their feelings on a 4-point Likert-type scale (range, from "not at all" to "very much so"). Two time-frames are possible for the STAI: the state version in which participants report how they feel "right now, that is, at this moment" and the trait version in which they report how they "generally" feel. According to the aim of the study, researchers should choose the time-frame version that best fit the research question.

Affect. The Positive and Negative Affect Schedule (PANAS) assesses both positive and negative affect (Watson et al., 1988). The PANAS is a 20-item self-administered questionnaire, 10 to positive affect (e.g., enthusiastic) and 10 to negative affect (e.g., scared). The score ranges from 10 to 50, where higher scores indicate higher either positive affect or negative affect. Participants rate to what extent statements describe their feelings on a 5-point Likert-type scale (range from "very slightly or not at all" to "extremely". Although there is a wide range of temporal instructions for the PANAS, the most common are "right now" and "in general"; i.e., state and trait directions. According to the aim of the study, researchers should choose the time-frame version that best fit the research question.

\section{Quality of life assessment}

Health-related quality of life has been shown to be lower in ME/CFS than in many other chronic conditions, including diabetes, stroke, osteoarthritis, rheumatoid arthritis, and even cancer (Falk Hvidberg et al., 2015; Kingdon et al., 2018). The RAND-36 (RAND corporation) is the publicly available version of the Short Form 36-item Health Survey (Optum, Inc., SF-36 ${ }^{\mathrm{TM}}$ ). Although an updated version of the SF-36TM is available (SF-36V2 ${ }^{\mathrm{TM}}$ ), all the 3 versions are similar and produce comparable scores (Laucis et al., 2015).

All the versions of this scale (SF-36 ${ }^{\mathrm{TM}}, \mathrm{SF}-36 \mathrm{~V} 2^{\mathrm{TM}}$, and RAND-36) measures health-related quality of health across three domains - functional status, well-being, and overall perceptions of health- with 8 subscales including physical functioning, role limitations due to physical problems, bodily pain, general health perceptions, vitality, social functioning, role limitations due to emotional problems, and mental health (. Hays et al., 1993; Hays \& Morales, 2001; Ware Jr. et al., 2007). From weighted sums in each subscale, two summary scales are derived, the physical component summary and the mental component summary, which give an indication of physical and mental capacity, respectively. Each scale is transformed into a 0-100 scale, where high scores indicate more disability. Scores are converted to $\mathrm{z}$ scores for comparison with the general population or other diseased populations, for which there is population-based normative data available.

This scale is easy to administer (approximately 10 minutes) and is among the most widely used generic measure of health-related quality of life (R. Hays \& Morales, 2001). The psychometric properties of the RAND-36 are adequate, clearly separating mental issues from physical issues (Gandek et al., 2004; R. Hays \& Morales, 2001). We recommend the use of the RAND-36 for measuring health-related quality of life in ME/CFS in Europe, which is publicly accessible in the following link: https://www.rand.org/health-care/surveys_tools/mos/36-item-short-form.html. 
Table 1. Recommended data collection tools for instrument-based profiling of fatigue, pain, and autonomic function symptoms

\begin{tabular}{|l|l|l|}
\hline $\begin{array}{l}\text { Recommended } \\
\text { data collection } \\
\text { tool }\end{array}$ & $\begin{array}{l}\text { Symptom } \\
\text { domains }\end{array}$ & Description \\
\hline $\begin{array}{l}\text { Visual Analog } \\
\text { Scales (VAS) }\end{array}$ & $\begin{array}{l}\text { fatigue } \\
\text { pain }\end{array}$ & $\begin{array}{l}\text { continuous scale anchored by 2 verbal descriptors } \\
\text { of each extreme (no fatigue/pain vs worse/pain } \\
\text { fatigue imaginable) }\end{array}$ \\
& $\begin{array}{l}\text { quantifiable measure of fatigue } \\
\text { valid and reliable } \\
\text { recommended time frame: previous 24 hours }\end{array}$ \\
\hline $\begin{array}{l}\text { Active standing } \\
\text { test }\end{array}$ & $\begin{array}{l}\text { autonomic } \\
\text { function }\end{array}$ & $\begin{array}{l}\text { heart rate and blood pressure measured at rest, then } \\
\text { immediately upon standing and at 1-2 minute intervals } \\
\text { for 10 minutes (or until no longer able) }\end{array}$ \\
\hline
\end{tabular}

\section{Visual Analog Scales}

Visual analogue scales (VAS) have become popular since first being validated (Hewlett et al., 2011) to use as quantitative measures to estimate subjective perceptions such as symptoms of fatigue because they are easily understood by participants, are quick to use and require very little reading skills. VAS are a continuous scale comprised of a horizontal line $100-\mathrm{mm}$ in length and anchored by two verbal descriptors: (0) 'no fatigue/pain at all' and (100) 'the worst imaginable fatigue/pain'. The patient is asked to place a line at the point that represents their fatigue/pain in the previous 24 hours. Due to its simplicity and adaptability, VAS measurements of symptom intensity have been widely used in diverse adult populations; e.g. in rheumatic diseases, chronic hepatitis-C infection, and systemic lupus (Estévez-López et al., 2017; Hewlett et al., 2011).

VAS have been shown to be a valid and reliable approach for having a rapid and quantitative assessment (Hewlett et al., 2011; Hawker et al., 2011). In the absence of a gold standards for measuring fatigue and pain, we recommended the use of VAS as standardised data collection tools for the instrument-based symptom profiling in people with ME/CFS.

\section{Active standing test}

Autonomic function is often altered in ME/CFS (Słomko et al., 2019). For instance, the experience of orthostatic intolerance is common in this population. Orthostatic intolerance is defined as the development of symptoms associated to changes in heart rate and blood pressure, when standing upright, which are relieved when reclining. We recommend the 10-minute standing test as a simple instrument-based tool to be used to capture orthostatic intolerance, and when feasible, we suggest extending the test to 20 minutes. Heart rate and blood pressure is measured at baseline while the person is supine for five minutes and again, at one or two-minute intervals, after passive standing up for up to 10 or 20 minutes, or until she or he can no longer tolerate the upright position (Reynolds et al., 2014). Capturing typical symptoms such as of dizziness, dyspnoea, and light-headedness simultaneously to an increase in pulse rate by at least 30 beats/min(adults) or to above 120 beats/minute enables the suggestion of a diagnosis of postural orthostatic tachycardia syndrome (POTS), a common co-morbidity among people with ME/CFS. Postural hypotension is indicated by a drop in systolic blood pressure of at least $20 \mathrm{mmHg}$ and/or a drop of diastolic blood pressure of at least $10 \mathrm{mmHg}$. 


\section{Additional tools for symptom profiling}

In order to have a comprehensive symptom profiling of ME/CFS, we agreed on the need to collect objective measurements of pain, autonomic function, physical activity and physical fitness. At the same time, we do recognise that these objective measurements require adequate equipment and resources, trained researchers, and time-availability, not only for the assessment but also for the dataset preparation. Thus, we suggest the following measurements only as complementary when ideal circumstances allow to do so.

Table 2. Additional recommended data collection tools for symptoms profiling

\begin{tabular}{|l|l|l|}
\hline $\begin{array}{l}\text { Recommended } \\
\text { data collection } \\
\text { tool }\end{array}$ & $\begin{array}{l}\text { Symptom } \\
\text { domains }\end{array}$ & Description \\
\hline $\begin{array}{l}\text { Heart rate } \\
\text { variability (HRV) }\end{array}$ & $\begin{array}{l}\text { autonomic } \\
\text { dysfunction }\end{array}$ & $\begin{array}{l}\text { non-invasive measure of autonomic nervous system } \\
\text { imbalances } \\
\text { requires a heart rate monitor and program to analyse } \\
\text { variation in time between each heartbeat }\end{array}$ \\
\hline Accelerometers & $\begin{array}{l}\text { movement- } \\
\text { related } \\
\text { behaviours }\end{array}$ & $\begin{array}{l}\text { non-invasive measure of physical activity, sedentary } \\
\text { time and sleep } \\
\text { requires device to be used by participant through } \\
\text { normal activity for } \geq 1 \text { week }\end{array}$ \\
\hline
\end{tabular}

Heart rate variability

Heart rate variability (HRV) is an objective measurement of autonomic function by means. Analysing the variability between $R$ waves ( $R-R$ interval) is a non-invasive indicator of autonomic dysfunction and has been associated with poor health (Evans et al., 2013; Meeus et al., 2013). The NINDS recommends a modified version that was described by Hyatt et al. in which the blood pressure is measured at 1-minute intervals, with the patient lying supine for the first five minutes and then standing up for ten minutes (or until no longer able) (Hyatt et al., 1975).

\section{Accelerometers}

Accelerometers provide objective measurements of physical activity, sedentary time and sleep (i.e., all the possible 24-h movement-related behaviours) (Tremblay et al., 2017.). Accelerometers are increasingly being used to objectively measure physical activity, sedentary time and sleep in diverse populations (Acosta et al., 2018; Migueles et al., 2018; Rodriguez-Ayllon et al., 2019; Segura-Jiménez et al., 2019), including ME/CFS (Meeus 2011, Rowlands 2016, Scheibenbogen 2018).

Physical activity and sedentary time are two independent yet related behaviours that occupy all waking hours of a day. Physical activity is any bodily movement that increases energy expenditure above resting energy expenditure (Caspersen et al., 1985; Tremblay et al., 2017). Sedentary time is the time spent in any waking behaviour and does not increase energy expenditure substantially while in a sitting, reclining or lying posture.

Although accelerometers were originally developed to measure physical activity, new technical and engineer applications have also made possible to evaluate sleep patterns. To the best of our knowledge, accelerometers have been used to objectively measure sleep in samples from the general population (e.g., from youths to older adults) (Adelantado-Renau et al., 2019; Cadenas- 
Sanchez et al., 2016; Fang et al., 2019) and chronic populations (e.g., diabetes and fibromyalgia) (Rosique-Esteban et al., 2018; Segura-Jiménez et al., 2015) but not in ME/CFS yet.

When circumstances allow to do so, we recommend to use accelerometers to objectively measure physical activity, sedentary time and sleep (i.e., all the possible 24-h movement-related behaviours) in ME/CFS in EUROMENE participating countries. As their utilization requires standardized data collection and processing of collected data (Migueles et al., 2017, 2018) , we warrant a further EUROMENE consensus on these issues.

\section{Final Considerations}

Through this research guide, we have set out minimum standards of data collection and offer recommendations for additional tools that can be used to enhance ME/CFS, where resources and local needs allow. We describe which general core information is essential to collect, how a provisional ME/CFS diagnosis should be made, and what assessments are used to confirm that diagnosis. We then set out questionnaire- and instrument-based tools used to profile symptoms and that an ME/CFS diagnosis is supported by the CDC- 1994, the CCC 2003, and/or the IOM criteria.

These questionnaires are freely available and easy to use, many but not all have been fully validated. They are easy to apply and deemed relevant for ME/CFS research, while consistent with current research practice. Given that for some tools there is only preliminary evidence of validity and reliability, to confirm their psychometrical properties in ME/CFS is warranted. Likewise, in Europe there co-exists a large number of languages and cultures for which questionnaires will need to be tailored for and validated in. Thus, we hope that the suggested tools will be translated to the language of European participating countries.

The suggested additional tools may provide valuable information in addressing a wide number of research questions. For instance, in case and control designs, the handgrip strength test could help to distinguish between people with and without ME/CFS and levels of severity of the disease; as it has been showed in fibromyalgia (Aparicio et al., 2011). In longitudinal studies, objectively measured physical activity might help to predict the progression of ME/CFS patients.

Overall, the simplicity of the suggested tools and because they are currently used in Europe, the present work will enable us to take a pragmatic decision to encourage participating European countries to adopt this guide. This will enable users to synchronise the identification of cases, data collection, and input of data and samples relating to ME/CFS research. By doing so, it will be possible to create an international database for collecting consistent and comparable epidemiological data to further facilitate scientific and clinical research. The CDE Project developed by the NINDS for ME/CFS research also outlines uniform formats by which clinical data can be systematically collected, analysed and shared across the research community. Many of the tools suggested by the NINDS are also recommended in this research guide; these include the clinical assessment (both physical examination and routine blood tests), the passive standing test to measure autonomic function, the RAND-36 to assess health-related quality of life, the PSQI to evaluate sleep quality, and the FAS and the FSS to quantify symptoms of fatigue. However, the adoption of the standardised data collection tools in the EUROMENE network also takes into account existing research practices among participating countries. This will make data systems and their use consistent with pre-existing approaches to data collection by participating countries, which have already been collecting data in standardised ways, while still allowing comparability with CDEs used in other parts of the world. 


\section{Author's Contributions}

$\mathrm{KM}, \mathrm{LN}$, and EL conceived and designed the outline of these recommendations. $\mathrm{KM}$, together with $\mathrm{FEL}$, obtained data collection tools from working group members and followed up where there were disagreements. KM and FEL wrote the final manuscript. All authors contributed to the final editing and have read and approved the final manuscript.

\section{Ethics statement}

All the authors declare no conflict of interests. The manuscript does not refer to any patient-related data or samples.

\section{References}

Acosta, F. M., Martinez-Tellez, B., Sanchez-Delgado, G., Migueles, J. H., Contreras-Gomez, M. A., Martinez-Avila, W. D., Merchan-Ramirez, E., Alcantara, J. M. A., Amaro-Gahete, F. J., Llamas-Elvira, J. M., \& Ruiz, J. R. (2018). Association of objectively measured physical activity with brown adipose tissue volume and activity in young adults. The Journal of Clinical Endocrinology \& Metabolism, 104(2), 223-233.

https://doi.org/10.1210/jc.2018-01312

Adelantado-Renau, M., Beltran-Valls, M. R., Migueles, J. H., Artero, E. G., Legaz-Arrese, A., Capdevila-Seder, A., \& Moliner-Urdiales, D. (2019). Associations between objectively measured and self-reported sleep with academic and cognitive performance in adolescents: DADOS study. Journal of Sleep Research, e12811. https://doi.org/10.1111/jsr.12811

Aparicio, V. A., Ortega, F. B., Heredia, J. M., Carbonell-Baeza, A., Sjöström, M., \& DelgadoFernandez, M. (2011). Handgrip Strength Test as a Complementary Tool in the Assessment of Fibromyalgia Severity in Women. Archives of Physical Medicine and Rehabilitation, 92(1), 83-88. https://doi.org/10.1016/J.APMR.2010.09.010

Arroll, M. A., Attree, E. A., O'Leary, J. M., \& Dancey, C. P. (2014). The delayed fatigue effect in myalgic encephalomyelitis/chronic fatigue syndrome (ME/CFS). Fatigue:

Biomedicine, Health \& Behavior, 2(2), 57-63.

https://doi.org/10.1080/21641846.2014.892755

Bakken, I. J., Tveito, K., Gunnes, N., Ghaderi, S., Stoltenberg, C., Trogstad, L., Haberg, S. E., \& Magnus, P. (2014). Two age peaks in the incidence of chronic fatigue syndrome/myalgic encephalomyelitis: a population-based registry study from Norway 2008-2012. BMC Med, 12(1), 167. https://doi.org/10.1186/s12916-014-0167-5

Beck, A., Steer, R., \& Brown, G. (1996). Manual for the Beck Depression Inventory-II. In Psychological Corporation. https://www.brown.edu/academics/publichealth/research/mens-health-initiative/bdiii

Beyond Myalgic Encephalomyelitis/Chronic Fatigue Syndrome: Redefining an Illness. (2015). Institute of Medicine of the National Academies. https://www.nap.edu/html/19012/MECFScliniciansguide.pdf

Brenu, E. W., van Driel, M. L., Staines, D. R., Ashton, K. J., Ramos, S. B., Keane, J., Klimas, N. G., \& Marshall-Gradisnik, S. M. (2011). Immunological abnormalities as potential biomarkers in Chronic Fatigue Syndrome/Myalgic Encephalomyelitis. J Transl Med, 9, 81. http://www.ncbi.nlm.nih.gov/pubmed/21619669 
Buysse, D. J., Reynolds, C. F., Monk, T. H., Berman, S. R., \& Kupfer, D. J. (1989). The Pittsburgh Sleep Quality Index: a new instrument for psychiatric practice and research. Psychiatry Research, 28(2), 193-213.

Cadenas-Sanchez, C., Mora-Gonzalez, J., Migueles, J. H. J. H., Martin-Matillas, M., GomezVida, J., Escolano-Margarit, M. V. M. V. M. V., Maldonado, J. J., Enriquez, G. M. G. M. M., Pastor-Villaescusa, B. B., de Teresa, C., Navarrete, S., Lozano, R. M. R. M. M., de Dios Beas-Jimenez, J., Estevez-Lopez, F., Mena-Molina, A., Heras, M. J. M. J. M. J., Chillon, P., Campoy, C., Munoz-Hernandez, V., ... Ortega, F. B. F. B. (2016). An exercise-based randomized controlled trial on brain, cognition, physical health and mental health in overweight/obese children (ActiveBrains project): Rationale, design and methods. Contemporary Clinical Trials, 47, 315-324.

https://doi.org/10.1016/j.cct.2016.02.007

Carruthers, B. M., van de Sande, M. I., De Meirleir, K. L., Klimas, N. G., Broderick, G., Mitchell, T., Staines, D., Powles, A. C. P., Speight, N., Vallings, R., Bateman, L., Baumgarten-Austrheim, B., Bell, D. S., Carlo-Stella, N., Chia, J., Darragh, A., Jo, D., Lewis, D., Light, A. R., ... Stevens, S. (2011). Myalgic encephalomyelitis: International Consensus Criteria. J Intern Med, 270(4), 327-338. https://doi.org/10.1111/j.13652796.2011.02428.x

Carruthers, B M, Jain, A. K., De Meirleir, K. L., Peterson, D. L., Klimas, N. G., Lerner, A. M., Bested, A. C., Flor-Henry, P., Joshi, P., Powles, A. C. P., Sherkey, J. A., \& van de Sande, M. I. (2003). Myalgic encephalomyelitis/chronic fatigue syndrome: clinical working case definition, diagnostic and treatment protocols. Journal of Chronic Fatigue Syndrome, 11(1), 7-115.

Carruthers, B M, van de Sande, M. I., De Meirleir, K. L., Klimas, N. G., Broderick, G., Mitchell, T., Staines, D., Powles, A. C., Speight, N., Vallings, R., Bateman, L., Baumgarten-Austrheim, B., Bell, D. S., Carlo-Stella, N., Chia, J., Darragh, A., Jo, D., Lewis, D., Light, A. R., ... Stevens, S. (2011). Myalgic encephalomyelitis: International Consensus Criteria. J Intern Med, 270(4), 327-338. https://doi.org/10.1111/j.13652796.2011.02428.x

Carruthers, Bruce M, Jain, A. K., De Meirleir, K. L., Peterson, D. L., Klimas, N. G., Lerner, A. M., Bested, A. C., Flor-Henry, P., Joshi, P., Powle, s A. P., Sherkey, J. A., van de Sande, M. I., Powles, A. C. P., Sherkey, J. A., van de Sande, M. I., Carruthers, Jain, A. K., De Meirleir, K. L., Peterson, D. L., ... van de Sande, M. I. (2003). Myalgic Encephalomyelitis/ Chronic Fatigue Syndrome: Clinical Working Case Definition, Diagnostic and Treatment Protocols. Journal of Chronic Fatigue Syndrome, 11(1), 7115. https://doi.org/10.1300/J092v11n01_02

Carruthers, Bruce M, Jain, A. K., DeMeirleir, K. L., Peterson, D., Klimas, N. G., Lerner, A. M., Bested, A. C., Flor-Henry, P., Joshi, P., Powles, A. P., Sherkey, J. A., \& van de Sande, M. I. (2003). Myalgic Encephalomyelitis/Chronic Fatigue Syndrome: Clinical Working Case Definition, Diagnostic and Treatment Protocols. Journal of Chronic Fatigue Syndrome, 11(1), 7-36. https://doi.org/10.1300/J092v11n01

Caspersen, C. J., Powell, K. E., \& Christenson, G. M. (1985). Physical activity, exercise, and physical fitness: definitions and distinctions for health-related research. Public Health Reports (Washington, D.C. : 1974), 100(2), 126-131. https://doi.org/10.2307/20056429

Castro-Piñero, J., Laurson, K. R., Artero, E. G., Ortega, F. B., Labayen, I., Ruperez, A. I., Zaqout, M., Manios, Y., Vanhelst, J., Marcos, A., Polito, A., Gonzalez-Gross, M., Widhalm, K., Moreno, L. A., Gutierrez, A., \& Ruiz, J. R. (2019). Muscle strength fieldbased tests to identify European adolescents at risk of metabolic syndrome: The HELENA study. Journal of Science and Medicine in Sport, 22(8), 929-934.

https://doi.org/10.1016/j.jsams.2019.04.008 
Castro-Piñero, J., Perez-Bey, A., Segura-Jiménez, V., Aparicio, V. A., Gómez-Martínez, S., Izquierdo-Gomez, R., Marcos, A., Ruiz, J. R., Marcos, A., Marcos, A., Castro-Piñero, J., Veiga, O. L., Bandres, F., Martinez-Gomez, D., Ruiz, J. R., Carbonell-Baeza, A., Gomez-Martinez, S., Santiago, C., Marcos, A., ... Gomez-Gallego, F. (2017). Cardiorespiratory Fitness Cutoff Points for Early Detection of Present and Future Cardiovascular Risk in Children. Mayo Clinic Proceedings, 92(12), 1753-1762. https://doi.org/10.1016/j.mayocp.2017.09.003

Chaudhuri, A., \& Behan, P. O. (2000). Neurological dysfunction in chronic fatigue syndrome. Journal of Chronic Fatigue Syndrome, 6(3/4), 51-68.

Estévez-López, F., Castro-Marrero, J., Wang, X., Bakken, I. J., Ivanovs, A., Nacul, L., Sepúlveda, N., Strand, E. B., Pheby, D., Alegre, J., Scheibenbogen, C., Shikova, E., Lorusso, L., Capelli, E., Sekulic, S., Lacerda, E., Murovska, M. on behalf of the European Network on ME/CFS (EUROMENE) (2018). Prevalence and incidence of myalgic encephalomyelitis/chronic fatigue syndrome in Europe-the Euro-epiME study from the European network EUROMENE: a protocol for a systematic review. BMJ Open, 8, 20817. https://doi.org/10.1136/bmjopen-2017-020817

Estévez-López, F., Gray, C. M. C. M. C. M., Segura-Jiménez, V., Soriano-Maldonado, A., Álvarez-Gallardo, I. C. I. C. I. C., Arrayás-Grajera, M. J. M. J., Carbonell-Baeza, A., Aparicio, V. A. V. A. V. A. V. A. V. a., Delgado-Fernández, M., Pulido-Martos, M., Estevez-Lopez, F., Gray, C. M. C. M. C. M., Segura-Jimenez, V., Soriano-Maldonado, A., Alvarez-Gallardo, I. C., Arrayas-Grajera, M. J., Carbonell-Baeza, A., Aparicio, V. A. V. A. V. A. V. A. V. a., Delgado-Fernandez, M., ... Pulido-Martos, M. (2015). Independent and combined association of overall physical fitness and subjective wellbeing with fibromyalgia severity: the al-Ándalus project. Quality of Life Research : An International Journal of Quality of Life Aspects of Treatment, Care and Rehabilitation, 24(8), 1865-1873. https://doi.org/10.1007/s11136-015-0917-7

Estévez-López, F., Rodriguez-Ayllon, M., Soriano-Maldonado, A., Acosta-Manzano, P., Segura-Jiménez, V., Álvarez-Gallardo, I. C., Pulido-Martos, M., Herrador-Colmenero, M., Geenen, R., Carbonell-Baeza, A., \& Delgado-Fernández, M. (2019). Lower Fatigue in Fit and Positive Women with Fibromyalgia: The al-Ándalus Project. Pain Medicine. https://doi.org/10.1093/pm/pny304

Estévez-López, F., Segura-Jiménez, V., Álvarez-Gallardo, I. C., Borges-Cosic, M., PulidoMartos, M., Carbonell-Baeza, A., Aparicio, V. A., Geenen, R., \& Delgado-Fernández, M. (2017). Adaptation profiles comprising objective and subjective measures in fibromyalgia: the al-Ándalus project. Rheumatology, 56(11), 2015-2024. https://doi.org/10.1093/rheumatology/kex302

Evans, S., Seidman, L. C., Ci Tsao, J., Lung, K. C., Zeltzer, L. K., \& Naliboff, B. D. (2013). Heart rate variability as a biomarker for autonomic nervous system response differences between children with chronic pain and healthy control children. Journal of Pain Research, 6-449. https://doi.org/10.2147/JPR.S43849

Falk Hvidberg, M., Brinth, L. S., Olesen, A. V, Petersen, K. D., \& Ehlers, L. (2015). The Health-Related Quality of Life for Patients with Myalgic Encephalomyelitis / Chronic Fatigue Syndrome (ME/CFS). PLoS ONE, 10(7), e0132421. https://doi.org/10.1371/journal.pone.0132421

Fang, B., Liu, H., Yang, S., Xu, R., \& Chen, G. (2019). Effect of Subjective and Objective Sleep Quality on Subsequent Peptic Ulcer Recurrence in Older Adults. Journal of the American Geriatrics Society, jgs.15871. https://doi.org/10.1111/jgs.15871

Fernandez Santos, J., Ruiz, J. R., Gonzalez-Montesinos, J. L., \& Castro-Piñero, J. (2016). Reliability and Validity of Field-Based Tests to Assess Upper-Body Muscular Strength 
in Children Aged 6-12 Years. Pediatric Exercise Science, 28(2), 331-340.

https://doi.org/10.1123/pes.2014-0196

Fontes, F., Gonçalves, M., Maia, S., Pereira, S., Severo, M., \& Lunet, N. (2017). Reliability and validity of the Pittsburgh Sleep Quality Index in breast cancer patients. Supportive Care in Cancer, 25(10), 3059-3066. https://doi.org/10.1007/s00520-017-3713-9

Fukuda, K., Straus, S. E., Hickie, I., Sharpe, M. C., Dobbins, J. G., \& Komaroff, A. (1994). The chronic fatigue syndrome: a comprehensive approach to its definition and study. International Chronic Fatigue Syndrome Study Group. Annals of Internal Medicine, 121(12), 953-959. https://doi.org/10.7326/0003-4819-121-12-199412150-00009

Gandek, B., Sinclair, S., Kosinski, M., \& Ware, J. (2004). Psychometric evaluation of the SF35 health survey in medicare managed care. Health Care Financing Review, 25(4), 525. http://martenstransport.nl/exceptioneel_transport/vergunningen

García-Hermoso, A., Ramírez-Campillo, R., \& Izquierdo, M. (2019). Is Muscular Fitness Associated with Future Health Benefits in Children and Adolescents? A Systematic Review and Meta-Analysis of Longitudinal Studies. Sports Medicine, 49(7), 1079-1094. https://doi.org/10.1007/s40279-019-01098-6

Gavilán-Carrera, B., Garcia da Silva, J., Vargas-Hitos, J. A., Sabio, J. M., Morillas-deLaguno, P., Rios-Fernández, R., Delgado-Fernández, M., \& Soriano-Maldonado, A. (2019). Association of physical fitness components and health-related quality of life in women with systemic lupus erythematosus with mild disease activity. PloS One, 14(2), e0212436. https://doi.org/10.1371/journal.pone.0212436

Harber, M. P., Kaminsky, L. A., Arena, R., Blair, S. N., Franklin, B. A., Myers, J., \& Ross, R. (2017). Impact of Cardiorespiratory Fitness on All-Cause and Disease-Specific Mortality: Advances Since 2009. Progress in Cardiovascular Diseases, 60(1), 11-20. https://doi.org/10.1016/j.pcad.2017.03.001

Hardcastle, S. L., Brenu, E. W., Johnston, S., Nguyen, T., Huth, T., Wong, N., Ramos, S., Staines, D., \& Marshall-Gradisnik, S. (2015). Characterisation of cell functions and receptors in Chronic Fatigue Syndrome/Myalgic Encephalomyelitis (CFS/ME). BMC Immunol, 16, 35. https://doi.org/10.1186/s12865-015-0101-4

Hawker, G. A., Mian, S., Kendzerska, T., \& French, M. (2011). Measures of adult pain: Visual Analog Scale for Pain (VAS Pain), Numeric Rating Scale for Pain (NRS Pain), McGill Pain Questionnaire (MPQ), Short-Form McGill Pain Questionnaire (SF-MPQ), Chronic Pain Grade Scale (CPGS), Short Form-36 Bodily Pain Scale (SF. Arthritis Care and Research, 63(SUPPL. 11), 240-252. https://doi.org/10.1002/acr.20543

Hays, R. D., Sherbourne, C. D., \& Mazel, R. (1993). The RAND 36-item health survey 1.0. https://www.rand.org/pubs/reprints/RP247.html

Hays, R., \& Morales, L. (2001). The RAND-36 measure of health-related quality of life. Ann Med, 33, 350-357. www.rand.org

Hewlett, S., Dures, E., \& Almeida, C. (2011). Measures of fatigue: Bristol Rheumatoid Arthritis Fatigue Multi-Dimensional Questionnaire (BRAF MDQ), Bristol Rheumatoid Arthritis Fatigue Numerical Rating Scales (BRAF NRS) for Severity, Effect, and Coping, Chalder Fatigue Questionnaire (CFQ), Checklist . Arthritis Care and Research, 63(SUPPL. 11). https://doi.org/10.1002/acr.20579

Hives, L., Bradley, A., Richards, J., Sutton, C., Selfe, J., Basu, B., Maguire, K., Sumner, G., Gaber, T., Mukherjee, A., \& Perrin, R. N. (2017). Can physical assessment techniques aid diagnosis in people with chronic fatigue syndrome/myalgic encephalomyelitis? A diagnostic accuracy study. BMJ Open, 7(11), 1-7. https://doi.org/10.1136/bmjopen- 


\section{7-017521}

Hunter, R. M., James, M., \& Paxman, J. (2017). Counting the Cost: Chronic Fatigue Syndrome/Myalgic Encephalomyelitis.

http://www.2020health.org/2020health/Publications/Publications-2017/OHC.html

Hyatt, K. H., Jacobson, L. B., \& Schneider, V. S. (1975). Comparison of 70 degrees tilt, LBNP, and passive standing as measrues of orthostatic tolerance. Aviation, Space, and Environmental Medicine, 46(6), 801-808. http://www.ncbi.nlm.nih.gov/pubmed/1156287

Ingerski, L. M., Modi, A. C., Hood, K. K., Pai, A. L., Zeller, M., Piazza-Waggoner, C., Driscoll, K. A., Rothenberg, M. E., Franciosi, J., \& Hommel, K. A. (2010). Health-Related Quality of Life Across Pediatric Chronic Conditions. Journal of Pediatrics, 156(4), 639-644. https://doi.org/10.1016/j.jpeds.2009.11.008

Institute of Medicine. (2015). Beyond Myalgic Encephalomyelitis/Chronic Fatigue Syndrome: Redefining an Illness. The National Academies Press.

http://www.nap.edu/catalog.php?record_id=19012

Institute of Medicine (IOM). (2015). Beyond Myalgic Encephalomyelitis/Chronic Fatigue Syndrome: Redefining an Illness. The National Academies Press.

http://www.nap.edu/catalog.php?record_id=19012

Jason, L A, Benton, M. C., Valentine, L., Johnson, A., \& Torres-Harding, S. (2008). The Economic impact of ME/CFS: Individual and societal costs. Dynamic Medicine, 7(6), 6. https://doi.org/10.1186/1476-5918-7-6

Jason, L A, Richman, J. A., Rademaker, A. W., Jordan, K. M., Plioplys, A. V, Taylor, R. R., McCready, W., Huang, C. F., \& Plioplys, S. (1999). A community-based study of chronic fatigue syndrome. Arch Intern Med, 159(18), 2129-2137.

http://www.ncbi.nlm.nih.gov/entrez/query.fcgi?cmd=Retrieve\&db=PubMed\&dopt=Citatio n\&list_uids $=10527290$

Jason, Leonard A, \& Brown, M. M. (2013). Sub-typing daily fatigue progression in chronic fatigue syndrome. Journal of Mental Health (Abingdon, England), 22(1), 4-11. https://doi.org/10.3109/09638237.2012.670879

Jason, Leonard A, McManimen, S., Sunnquist, M., Newton, J. L., \& Strand, E. B. (2017). Examining those Meeting IOM Criteria Versus IOM Plus Fibromyalgia. Neurology (ECronicon), 5(1), 19-28.

Jason, Leonard A, Paavola, E., Porter, N., \& Morello, M. L. (2010). Frequency and content analysis of chronic fatigue syndrome in medical text books. Australian Journal of Primary Health, 16(2), 174-178. https://doi.org/10.1071/py09023

Jason, Leonard A, Sunnquist, M., Brown, A., Furst, J., Cid, M., Farietta, J., Kot, B., Bloomer, C., Nicholson, L., Williams, Y., Jantke, R., Newton, J. L., \& Strand, E. B. (2015). Factor Analysis of the DePaul Symptom Questionnaire: Identifying Core Domains. Journal of Neurology and Neurobiology, 1(4). https://doi.org/10.16966/2379-7150.114

Johns, M. W. (n.d.). About the ESS - Epworth Sleepiness Scale.

Kato, D. J., Rodgers, W. M., Stickland, M. K., \& Haennel, R. G. (2012). Impact of Peak Oxygen Uptake and Muscular Fitness on the Performance of Activities of Daily Living in Patients With Chronic Obstructive Pulmonary Disease. Journal of Cardiopulmonary Rehabilitation and Prevention, 32(6), 400-404. https://doi.org/10.1097/HCR.0b013e31826ba501

Kennedy, G., Underwood, C., \& Belch, J. J. F. (2010). Physical and functional impact of chronic fatigue syndrome/myalgic encephalomyelitis in childhood. Pediatrics, 125(6), 
e1324-e1330. https://doi.org/10.1542/peds.2009-2644

Kingdon, C. C., Bowman, E. W., Curran, H., Nacul, L., \& Lacerda, E. M. (2018). Functional Status and Well-Being in People with Myalgic Encephalomyelitis/Chronic Fatigue Syndrome Compared with People with Multiple Sclerosis and Healthy Controls. PharmacoEconomics - Open. https://doi.org/10.1007/s41669-018-0071-6

Krupp, L. B., LaRocca, N. G., Muir-Nash, J., \& Steinberg, A. D. (1989). The fatigue severity scale. Application to patients with multiple sclerosis and systemic lupus erythematosus. Arch Neurol, 46(10), 1121-1123.

http://www.ncbi.nlm.nih.gov/entrez/query.fcgi?cmd=Retrieve\&db=PubMed\&dopt=Citatio n\&list_uids $=2803071$

Lacerda, E. M., Bowman, E. W., Cliff, J. M., Kingdon, C. C., King, E. C., Lee, J.-S., Clark, T. G., Dockrell, H. M., Riley, E. M., Curran, H., \& Nacul, L. (2017). The UK ME/CFS Biobank for biomedical research on Myalgic Encephalomyelitis/Chronic Fatigue Syndrome (ME/CFS) and Multiple Sclerosis. Open Journal of Bioresources, 4. https://doi.org/10.5334/ojb.28

Lacerda, E. M., Kingdon, C. C., Bowman, E. W., \& Nacul, L. (2018). Using a participatory approach to develop and implement the UK ME/CFS Biobank. Fatigue: Biomedicine, Health \& Behavior, 6(1), 1-4. https://doi.org/10.1080/21641846.2018.1396021

Laucis, N. C., Hays, R. D., \& Bhattacharyya, T. (2015). Scoring the SF-36 in Orthopaedics: A Brief Guide. BY THE JOURNAL OF BONE AND JOINT SURGERY, 97, 1628-1662. https://doi.org/10.2106/JBJS.0.00030

Lloyd, A. R., \& Pender, H. (1992). The economic impact of chronic fatigue syndrome. Med J Aust, 157(9), 599-601. https://www.ncbi.nlm.nih.gov/pubmed/1406420

Meeus, M., Goubert, D., De Backer, F., Struyf, F., Hermans, L., De Wandele, I., Da Silva, H., \& Calders, P. (2013). Heart rate variability in patients with fibromyalgia and patients with chronic fatigue syndrome: A systematic review. https://doi.org/10.1016/j.semarthrit.2013.03.004

Meeus, M., \& Nijs, J. (2007). Central sensitization: a biopsychosocial explanation for chronic widespread pain in patients with fibromyalgia and chronic fatigue syndrome. Clin Rheumatol, 26, 465-473. https://doi.org/10.1007/s10067-006-0433-9

Migueles, J. H., Cadenas-Sanchez, C., Ekelund, U., Delisle Nyström, C., Mora-Gonzalez, J., Löf, M., Labayen, I., Ruiz, J. R., \& Ortega, F. B. (2017). Accelerometer Data Collection and Processing Criteria to Assess Physical Activity and Other Outcomes: A Systematic Review and Practical Considerations. Sports Medicine (Auckland, N.Z.), 47(9), 18211845. https://doi.org/10.1007/s40279-017-0716-0

Migueles, J. H., Cadenas-Sanchez, C., Tudor-Locke, C., Löf, M., Esteban-Cornejo, I., Molina-Garcia, P., Mora-Gonzalez, J., Rodriguez-Ayllon, M., Garcia-Marmol, E., Ekelund, U., \& Ortega, F. B. (2018). Comparability of published cut-points for the assessment of physical activity: Implications for data harmonization. Scandinavian Journal of Medicine \& Science in Sports, 29(4), sms.13356. https://doi.org/10.1111/sms.13356

Mollayeva, T., Thurairajah, P., Burton, K., Mollayeva, S., Shapiro, C. M., \& Colantonio, A. (2016). The Pittsburgh sleep quality index as a screening tool for sleep dysfunction in clinical and non-clinical samples: A systematic review and meta-analysis. Sleep Medicine Reviews, 25, 52-73. https://doi.org/10.1016/j.smrv.2015.01.009

Morris, G., \& Maes, M. (2013). Myalgic encephalomyelitis/chronic fatigue syndrome and encephalomyelitis disseminata/multiple sclerosis show remarkable levels of similarity in 
phenomenology and neuroimmune characteristics. BMC Med, 11, 205. https://doi.org/10.1186/1741-7015-11-205

Nacul, L., Lacerda, E. M., Kingdon, C. C., Curran, H., \& Bowman, E. W. (2017). How have selection bias and disease misclassification undermined the validity of myalgic encephalomyelitis/chronic fatigue syndrome studies? Journal of Health Psychology, 1359105317695803. https://doi.org/10.1177/1359105317695803

Nacul, L., O’Boyle, S., Palla, L., Nacul, F. E., Mudie, K., Kingdon, C. C., Cliff, J. M., Clark, T. G., Dockrell, H. M., \& Lacerda, E. M. (2020). How Myalgic Encephalomyelitis/Chronic Fatigue Syndrome (ME/CFS) Progresses: The Natural History of ME/CFS. Frontiers in Neurology, 1, 826. https://doi.org/10.3389/fneur.2020.00826

Nacul, L C, Lacerda, E. M., Pheby, D., Campion, P., Molokhia, M., Fayyaz, S., Leite, J. C., Poland, F., Howe, A., \& Drachler, M. L. (2011). Prevalence of myalgic encephalomyelitis/chronic fatigue syndrome (ME/CFS) in three regions of England: a repeated cross-sectional study in primary care. BMC Med, 9, 91. https://doi.org/10.1186/1741-7015-9-91

Nacul, Luis C., Lacerda, E. M., Campion, P., Pheby, D., Drachler, M. D. L., Leite, J. C., Poland, F., Howe, A., Fayyaz, S., \& Molokhia, M. (2011). The functional status and well being of people with myalgic encephalomyelitis/chronic fatigue syndrome and their carers. BMC Public Health, 11(1), 402. https://doi.org/10.1186/1471-2458-11-402

Nacul, Luis Carlos, Mudie, K., Kingdon, C. C., Clark, T. G., \& Lacerda, E. M. (2018). Hand Grip Strength as a Clinical Biomarker for ME/CFS and Disease Severity. Frontiers in Neurology, 9(NOV). https://doi.org/10.3389/fneur.2018.00992

NINDS Common Data Elements. (2018). Myalgic Encephalomyelitis/Chronic Fatigue Syndrome Standards - NINDS Common Data Elements. https://www.commondataelements.ninds.nih.gov/MECFS.aspx\#tab=Data_Standards

Ortega, F. B., Ruiz, J. R., Castillo, M. J., \& Sjöström, M. (2008). Physical fitness in childhood and adolescence: a powerful marker of health. International Journal of Obesity, 32(1), 1-11. https://doi.org/10.1038/sj.ijo.0803774

Park, S., Han, H. S., Kim, G.-U., Kang, S. S., Kim, H.-J., Lee, M., Park, S. H., Choi, K. H., Kim, S.-H., \& Yeom, J. S. (2017). Relationships among Disability, Quality of Life, and Physical Fitness in Lumbar Spinal Stenosis: An Investigation of Elderly Korean Women. Asian Spine Journal, 11(2), 256. https://doi.org/10.4184/asj.2017.11.2.256

Pheby, D. F. H., Araja, D., Berkis, U., Brenna, E., Cullinan, J., de Korwin, J.-D., Gitto, L., Hughes, D. A., Hunter, R. M., Trepel, D., \& Wang-Steverding, X. (2020). The Development of a Consistent Europe-Wide Approach to Investigating the Economic Impact of Myalgic Encephalomyelitis (ME/CFS): A Report from the European Network on ME/CFS (EUROMENE). Healthcare (Basel, Switzerland), 8(2). https://doi.org/10.3390/healthcare8020088

Rahman, K., Burton, A., Galbraith, S., Lloyd, A., \& Vollmer-Conna, U. (2011). Sleep-wake behavior in chronic fatigue syndrome. Sleep., 34(5), 671-8.

Reynolds, G. K., Lewis, D. P., Richardson, A. M., \& Lidbury, B. A. (2014). Comorbidity of postural orthostatic tachycardia syndrome and chronic fatigue syndrome in an Australian cohort. Journal of Internal Medicine, 275(4), 409-417. https://doi.org/10.1111/joim.12161

Rodriguez-Ayllon, M., Cadenas-Sánchez, C., Estévez-López, F., Muñoz, N. E., MoraGonzalez, J., Migueles, J. H., Molina-García, P., Henriksson, H., Mena-Molina, A., Martínez-Vizcaíno, V., Catena, A., Löf, M., Erickson, K. I., Lubans, D. R., Ortega, F. B., 
\& Esteban-Cornejo, I. (2019). Role of Physical Activity and Sedentary Behavior in the Mental Health of Preschoolers, Children and Adolescents: A Systematic Review and Meta-Analysis. Sports Medicine, 1-28. https://doi.org/10.1007/s40279-019-01099-5

Rosique-Esteban, N., Papandreou, C., Romaguera, D., Warnberg, J., Corella, D., MartínezGonzález, M. Á., Díaz-López, A., Estruch, R., Vioque, J., Arós, F., Garcia-Rios, A., Bueno-Cavanillas, A., Vidal, J., Serra-Majem, L., Sibai, A. A., Tinahones, F. J., Martínez, J. A., Ordovás, J. M., Tur, J. A., ... Salas-Salvadó, J. (2018). Cross-sectional associations of objectively-measured sleep characteristics with obesity and type 2 diabetes in the PREDIMED-Plus trial. Sleep, 41(12).

https://doi.org/10.1093/sleep/zsy190

Ruiz, J. R., Sui, X., Lobelo, F., Lee, D.-C., Morrow, J. R., Jackson, A. W., Hébert, J. R., Matthews, C. E., Sjöström, M., \& Blair, S. N. (2009). Muscular strength and adiposity as predictors of adulthood cancer mortality in men. Cancer Epidemiology, Biomarkers \& Prevention: A Publication of the American Association for Cancer Research, Cosponsored by the American Society of Preventive Oncology, 18(5), 1468-1476. https://doi.org/10.1158/1055-9965.EPI-08-1075

Ruiz, J. R., Sui, X., Lobelo, F., Morrow, J. R., Jackson, A. W., Sjöström, M., \& Blair, S. N. (2008). Association between muscular strength and mortality in men: prospective cohort study. BMJ (Clinical Research Ed.), 337(jul01 2), a439. https://doi.org/10.1136/bmj.a439

ScienceforME. (2018). Is the NIH/CDC going to use the right PEM definition for all their future research? Do patients need to act?

Segura-Jiménez, V., Camiletti-Moirón, D., Munguía-Izquierdo, D., Álvarez-Gallardo, I. C., Ruiz, J. R., Ortega, F. B., \& Delgado-Fernández, M. (2015). Agreement between selfreported sleep patterns and actigraphy in fibromyalgia and healthy women. Clinical and Experimental Rheumatology, 33(1 Suppl 88), S58-67. http://www.ncbi.nlm.nih.gov/pubmed/25786045

Segura-Jiménez, V., Estévez-López, F., Castro-Piñero, J., Álvarez-Gallardo, I. C., SorianoMaldonado, A., Borges-Cosic, M., \& Delgado-Fernández, M. (2019). Association of Patterns of Moderate-to-Vigorous Physical Activity Bouts With Pain, Physical Fatigue, and Disease Severity in Women With Fibromyalgia: the al-Ándalus Project. Archives of Physical Medicine and Rehabilitation. https://doi.org/10.1016/j.apmr.2018.12.019

Shanks, L., Jason, L. A., Evans, M., Brown, A., Stewart, J. M., York, N., Lambert, G. W., \& Heart, B. (2013). Cognitive impairments associated with CFS and POTS. https://doi.org/10.3389/fphys.2013.00113

Sletten, D. M., Suarez, G. A., Low, P. A., Mandrekar, J., \& Singer, W. (2012). COMPASS 31: A refined and abbreviated composite autonomic symptom score. Mayo Clinic Proceedings, 87(12), 1196-1201. https://doi.org/10.1016/j.mayocp.2012.10.013

Słomko, J., Newton, J. L., Kujawski, S., Tafil-Klawe, M., Klawe, J., Staines, D., MarshallGradisnik, S., \& Zalewski, P. (2019). Prevalence and characteristics of chronic fatigue syndrome/myalgic encephalomyelitis (CFS/ME) in Poland: a cross-sectional study. BMJ Open, 9, 23955. https://doi.org/10.1136/bmjopen-2018-023955

Spielberger, C., Gorsuch, R., \& Lushene, R. (1970). The state-trait anxiety inventory (test manual). In Palo Alto, CA, Consulting Psychologists.

Tremblay, M. S., Aubert, S., Barnes, J. D., Saunders, T. J., Carson, V., Latimer-Cheung, A. E., Chastin, S. F. M., Altenburg, T. M., \& Chinapaw, M. J. M. (2017). Sedentary Behavior Research Network (SBRN)-Terminology Consensus Project process and outcome. https://doi.org/10.1186/s12966-017-0525-8 
Twisk, F. N. (2015). Accurate diagnosis of myalgic encephalomyelitis and chronic fatigue syndrome based upon objective test methods for characteristic symptoms. World Journal of Methodology, 5(2), 68. https://doi.org/10.5662/wjm.v5.i2.68

Valdez, A. R., Hancock, E. E., Adebayo, S., Kiernicki, D. J., Proskauer, D., Attewell, J. R., Bateman, L., DeMaria, A., Lapp, C. W., Rowe, P. C., \& Proskauer, C. (2018). Estimating Prevalence, Demographics, and Costs of ME/CFS Using Large Scale Medical Claims Data and Machine Learning. Frontiers in Pediatrics, 6, 412. https://doi.org/10.3389/fped.2018.00412

Valko, P. O., Bassetti, C. L., Bloch, K. E., Held, U., \& Baumann, C. R. (2008). Validation of the fatigue severity scale in a Swiss cohort. Sleep, 31(11), 1601-1607. http://www.ncbi.nlm.nih.gov/pubmed/19014080

van der Schaaf, M. E., De Lange, F. P., Schmits, I. C., Geurts, D. E. M., Roelofs, K., van der Meer, J. W. M., Toni, I., \& Knoop, H. (2017). Prefrontal Structure Varies as a Function of Pain Symptoms in Chronic Fatigue Syndrome. Biological Psychiatry, 81(4), 358-365. https://doi.org/10.1016/J.BIOPSYCH.2016.07.016

Varni, J. W., Limbers, C. A., \& Burwinkle, T. M. (2007). Impaired health-related quality of life in children and adolescents with chronic conditions: A comparative analysis of 10 disease clusters and 33 disease categories/severities utilizing the PedsQL ${ }^{\mathrm{TM}} 4.0$ Generic Core Scales. Health and Quality of Life Outcomes, 5, 43.

https://doi.org/10.1186/1477-7525-5-43

Vincent, A., Brimmer, D. J., Whipple, M. O., Jones, J. F., Boneva, R., Lahr, B. D., Maloney, E., St, J. L., Sauver, ;, \& Reeves, W. C. (2012). Prevalence, Incidence, and Classification of Chronic Fatigue Syndrome in Olmsted County, Minnesota, as Estimated Using the Rochester Epidemiology Project. JMCP, 87, 1145-1152. https://doi.org/10.1016/j.mayocp.2012.08.015

Ware Jr., J. E., Kosinski, M. A., Bjorner, J. B., Turner-Bowker, D. M., Gandek, B., Maruish, M. E., Ware Jr, J. E., Kosinski, M. A., Bjorner, J. B., Turner-Bowker, D. M., Gandek, B., Maruish, M. E., Ware, J. E. J., Kosinski, M. A., Bjorner, J. B., Turner-Bowke, D. M., Gandek, B., \& Maruish, M. E. (2007). User's manual for the SF-36v2TM health survey. QualityMetric Incorporated.

Watson, D., Clark, L. A., \& Tellegen, A. (1988). Development and validation of brief measures of positive and negative affect: the PANAS scales. Journal of Personality and Social Psychology, 54(6), 1063-1070.

Winger, A., Kvarstein, G., Wyller, V. B., Ekstedt, M., Sulheim, D., Fagermoen, E., Småstuen, M. C., \& Helseth, S. (2015). Health related quality of life in adolescents with chronic fatigue syndrome: a cross-sectional study. https://doi.org/10.1186/s12955-015-0288-3 